\title{
Compact Patch Antenna Array using Defective Ground Structure on Feedline
}

\author{
Swati Gupta \\ M. Tech \\ APJ Technical University, \\ Lucknow
}

\author{
Dhirendra Kumar \\ Head of ECE Department, \\ RKGIT, Ghaziabad \\ APJ Technical University, Lucknow
}

\begin{abstract}
The paper presented here is dealing with the design of compact patch antenna array using defective ground structure (DGS) on feed line. The array of 1:2 patch antenna with microstrip line feeding technique is proposed. A systematic approach has been taken to design the antenna array using defective ground structure on the feed line to achieve the return loss up to $-56 \mathrm{~dB}$. The designed antenna is suitable for WIMAX application.
\end{abstract}

\section{Keywords}

Antenna array, Defective ground structure, IE3D simulation, Microstrip patch antenna.

\section{INTRODUCTION}

In modern wireless communication systems, the compact patch antenna array has been playing a very important role for wireless service requirements [1]. Antennas which are used in these applications should be low profile, light weight, low volume and broad bandwidth [2]. To meet these requirements, microstrip antenna is preferred. The microstrip antenna was first proposed by G.A. Deschamps in 1953[3], but didn't become practical until the1970s when it was developed further by researchers such as Robert E. Munson [4] and others using low-loss soft substrate materials.

Microstrip patch antenna consists of a dielectric substrate, with a ground plane on the other side. Due to its advantages such as low weight [5], low profile planar configuration, low fabrication costs and capability to integrate with microwave integrated circuits technology [6], the microstrip patch antenna is very well suited for applications such as biomedical applications, aerospace, Radar systems and satellite communications systems. Although patch antenna has numerous advantages, it has also some drawbacks such as restricted bandwidth, low gain, excitation of surface waves and a potential decrease in radiation pattern [7]. Different feeding techniques like inset feed, circular coaxial probe feed, proximity coupled feed [8], [9] are used to improve the gain of microstrip patch antenna. Inhibiting characteristics of a single microstrip patch, like low gain, directivity and return loss make it more popular for array configuration [10]. Higher directivity is the basic requirement in point to point communications, radars and space application and for this, an assemblage of antennas, called an array, is used. An antenna array (also called a "phased array") is a set of 2 or more antennas. The signals from the antennas are combined or processed in order to achieve improved performance over that of a single antenna [11].

Recently Defective ground structures (DGS) have come into play to improve microstrip patch antenna array characteristics. DGS is an intentionally etched defect into ground plane. The purpose of using DGS as a technique to improve the antenna performance on the basis of basic parameters is to make use of the ground plane itself to prove a filter effect. This effect suppresses the mutual coupling between antennas thereby improve the antenna performance [12][13]. DGS are introduced to improve antenna performance characteristics like size reduction, gain, return loss and directivity, and it is also used in reduction of mutual coupling between antenna elements. DGS may come in number of geometries and sizes depending upon their mode of application, as well as the frequency of operation. [14], [15].

In this paper, the design of single, 1:2 array microstrip antennas with microstrip line as feeding method is presented. To enhance the performance of 1:2 antenna, experiments with DGS on feed line have been done with variation on DGS dimensions and its placing on antenna, and return loss of $56 \mathrm{~dB}$ is achieved which has displayed improved performance with respect to 1:2 antenna without defected ground. Quarterwave transformer is used to match the feeding line to the antennas. The center frequency is considered as $5 \mathrm{GHz}$ which is suitable for Wireless communication.

\section{ANTENNA DESIGN}

\subsection{Physical Parameters Calculation}

Some important antenna parameters can be calculated by the transmission line method [11], and is explained to simplify the design process. The three essential parameters for the design of a rectangular microstrip patch Antenna are: Frequency of operation $\left(\mathrm{f}_{\mathrm{c}}=5 \mathrm{GHz}\right)$, substrate dielectric constant $\left(\varepsilon_{\mathrm{r}}=4.5\right)$ and height $(\mathrm{h}=1.5 \mathrm{~mm})$. The width of the microstrip patch has been calculated using the equation suggested [11], as $\mathrm{w}=$ $18.09 \mathrm{~mm}$, The length of the patch can be calculated only if the effective dielectric constant is known, and the effective dielectric constant can be calculated as effective dielectric constant $=3.99$, The extension of the length due to fringing effect is $0.6807 \mathrm{~mm}$, The effective length $\mathrm{L}_{\text {eff }}=15.02253 \mathrm{~mm}$. The physical length of the patch would be $13.66 \mathrm{~mm}$ after considering the fringing effect.

The overall area of the structure is hence obtained as $13.66 \times 18.09 \mathrm{~mm}^{2}$. Figure 1 shows the structure of single antenna with inset feed line. The return loss of this single patch is obtained as $-15 \mathrm{~dB}$ is achieved, to further improved the result, addition of the transformer coupled is done as shown in Figure 2 The reflection become again lesser as the return loss of $-33 \mathrm{~dB}$ is obtained. Table 1 shows the summarize form of single patch antenna. The dimension of the antenna with single patch is given in Table 1 . 
Table 1: Dimensions of single patch antenna with inset feed and transformer coupled

\begin{tabular}{|l|l|l|l|l|l|l|}
\hline $\begin{array}{l}\mathrm{L} \\
(\mathrm{mm})\end{array}$ & $\begin{array}{l}\mathrm{W} \\
(\mathrm{mm})\end{array}$ & $\begin{array}{l}\mathrm{L}^{\prime}=\mathrm{x} \\
(\mathrm{mm})\end{array}$ & $\begin{array}{l}\mathrm{W}_{0}=\mathrm{y} \\
(\mathrm{mm})\end{array}$ & $\begin{array}{l}\mathrm{L}^{\prime} \\
(\mathrm{mm})\end{array}$ & $\begin{array}{l}\mathrm{W}^{\prime} \\
(\mathrm{mm})\end{array}$ & $\begin{array}{c}\mathrm{S} 11 \\
(\mathrm{~dB})\end{array}$ \\
\hline 13.66 & 18.09 & 8 & 4.5 & 10 & 2.8 & -33 \\
\hline
\end{tabular}

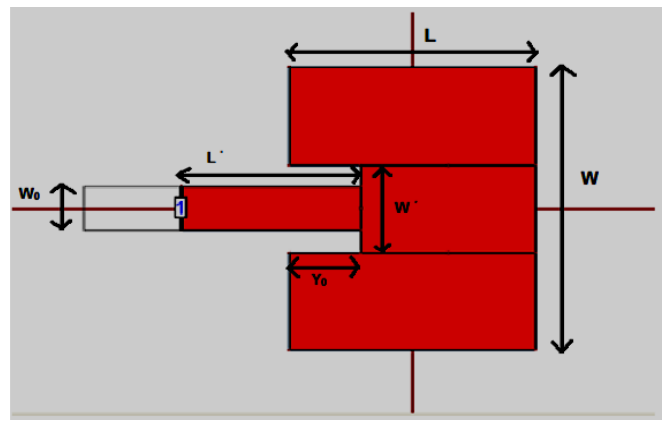

Fig.1. Single Inset feed patch antenna

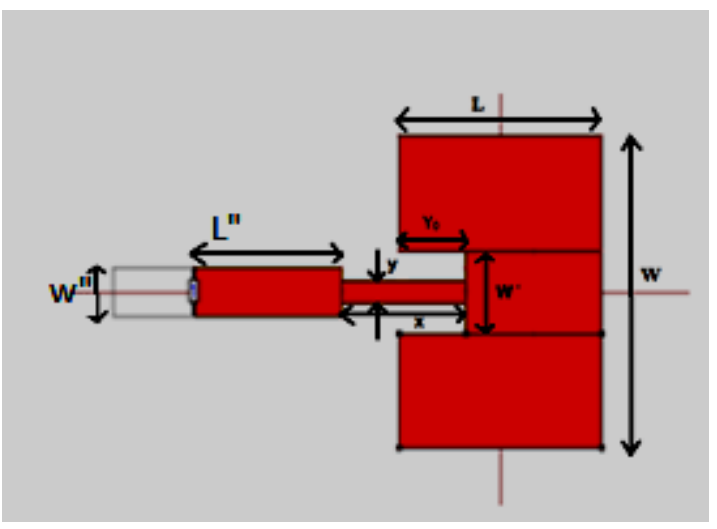

Fig.2. Single Transformer Coupled Patch Antenna

\subsection{1:2 Patch Antenna Array}

In the preceding section a single patch antenna is designed with transformer coupled. The reflection characteristics may be improved by arranging the patches as shown in Figure 3. The structure shown in Figure 3 may be considered as 1:2 patch array as the main feed line is same for both the patches. The dimensions are listed in Table 2. The designed structure is simulated using MOM based full wave electromagnetic simulation software. The simulated S11 parameters are shown in Figure 4 and the 3-D radiation pattern is shown in Figure 5.

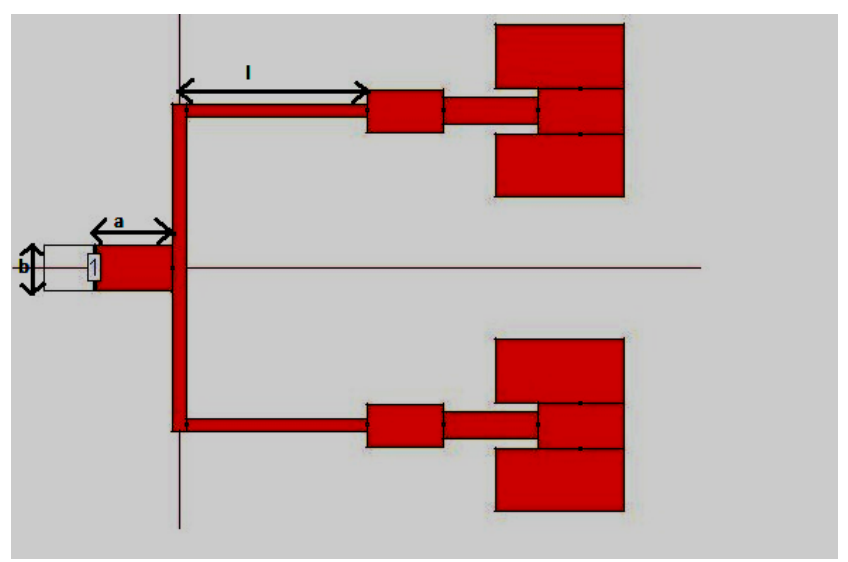

Fig.3: Geometry of 1:2 Patch Antenna Array
Table 2: Dimensions of 1:2 patch array

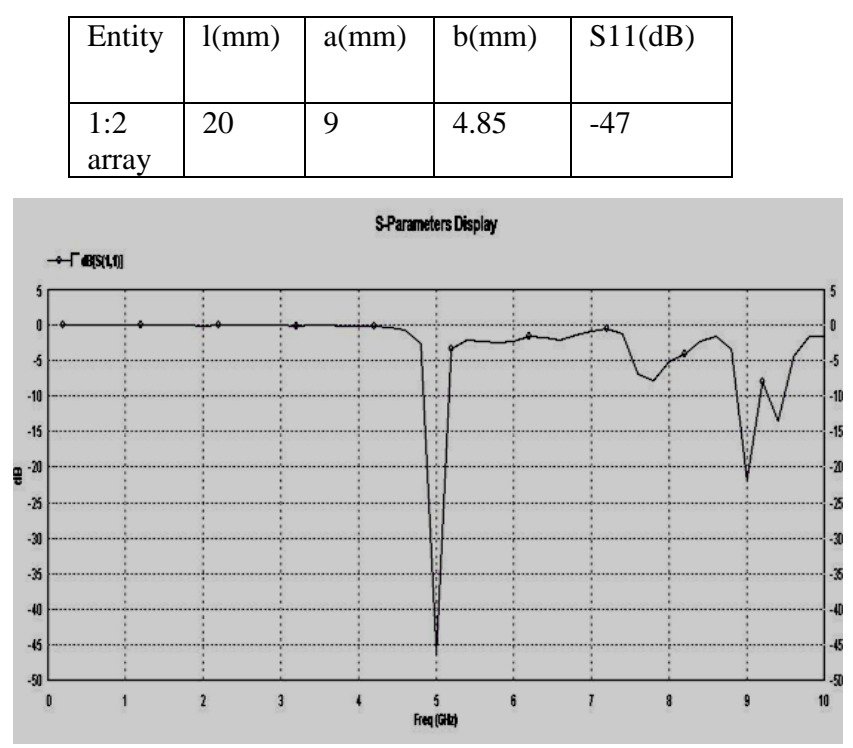

Fig.4 S-Parameter of 1:2 Patch Antenna Array

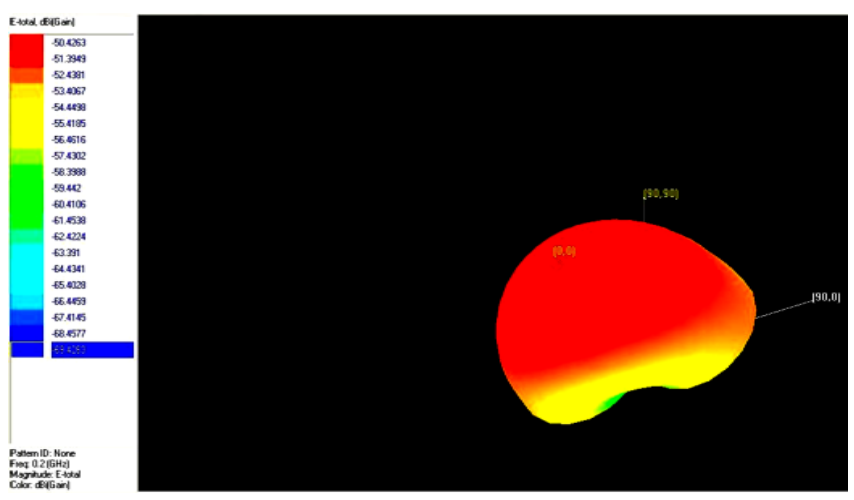

Fig. 5: Radiation pattern of 1:2 Patch Antenna Array

\subsection{1:2 Patch Antenna Array with Defective Ground Structure (DGS)}

Figure 6 as given below shows the 3-D structure 1:2 array with defective ground structure on feed line. First the basic structure of 1:2 patch antenna array is taken as shown in above Figure 3 after that defect of square shape on the ground plane is etched. The dimension of the square cut is $1 \times 1 \mathrm{~mm}^{2}$.

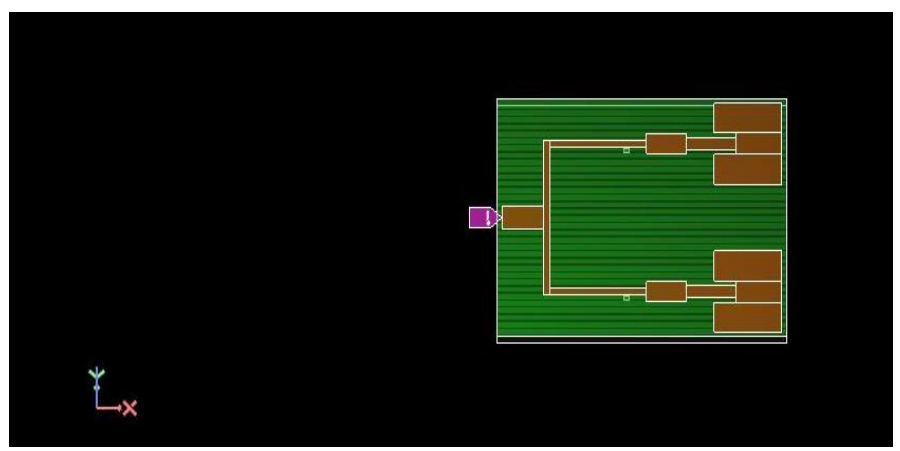

Fig. 6: 3-D structure of 1:2 Patch Antenna Array with DGS 


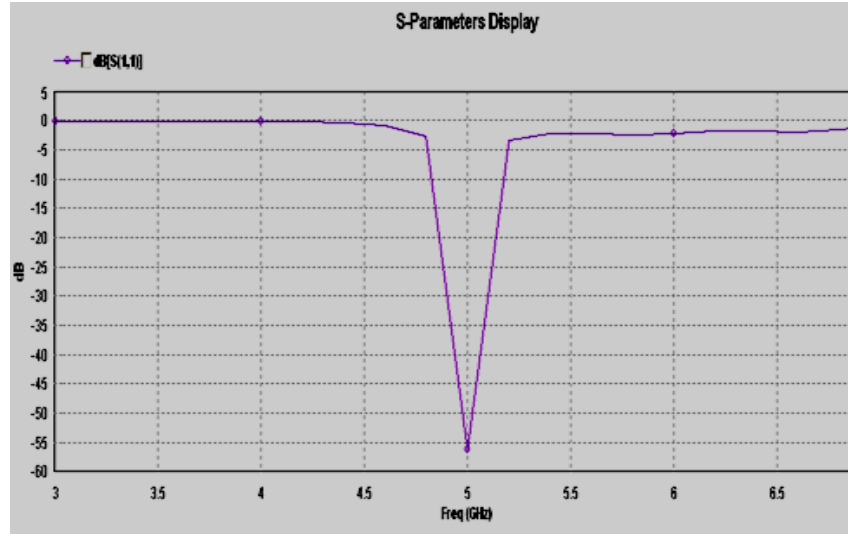

Fig. 7: S-Parameter of 1:2 Patch Antenna Array with DGS

\section{DISSCUSSION}

The simulated results of 1:2 patch array without DGS and 1:2 patch array with DGS are summarized and listed in Table 3

Table 3: summarized results of the designed antennas

\begin{tabular}{|c|c|c|c|c|c|}
\hline Entity & $\begin{array}{c}\text { S11 } \\
(\mathrm{dB})\end{array}$ & $\begin{array}{c}\text { Gain } \\
(\mathrm{dB})\end{array}$ & $\begin{array}{c}\text { Directivit } \\
\mathrm{y}(\mathrm{dB})\end{array}$ & $\begin{array}{c}\text { Antenna } \\
\text { efficienc } \\
\mathrm{y} \\
(\%)\end{array}$ & $\begin{array}{c}\text { radiation } \\
\text { efficienc } \\
\mathrm{y} \\
(\%)\end{array}$ \\
\hline $\begin{array}{c}1: 2 \text { patch } \\
\text { antenna } \\
\text { array }\end{array}$ & -47 & 9 & 9.5 & 80 & 78 \\
\hline $\begin{array}{c}1: 2 \\
\text { patch } \\
\text { antenna } \\
\text { array } \\
\text { with } \\
\text { DGS }\end{array}$ & -56 & 8.7 & 9.7 & 80 & 78 \\
\hline
\end{tabular}

The antenna with DGS has enhanced directivity with very small cost of antenna gain. The antenna efficiency and radiation efficiency is observed almost similar.

\section{SIMULATION RESULTS OF 1:2 PATCH ANTENNA ARRAY WITH DGS}

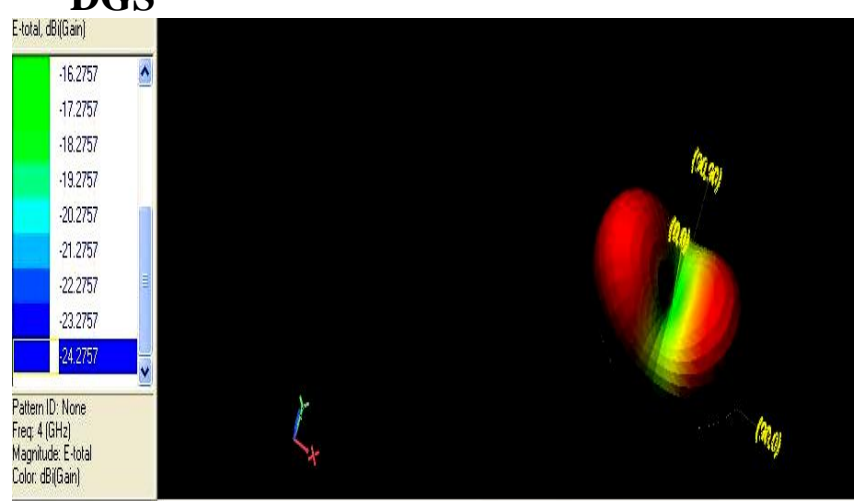

Fig. 8: Radiation pattern of 1:2 Patch Antenna Array with DGS

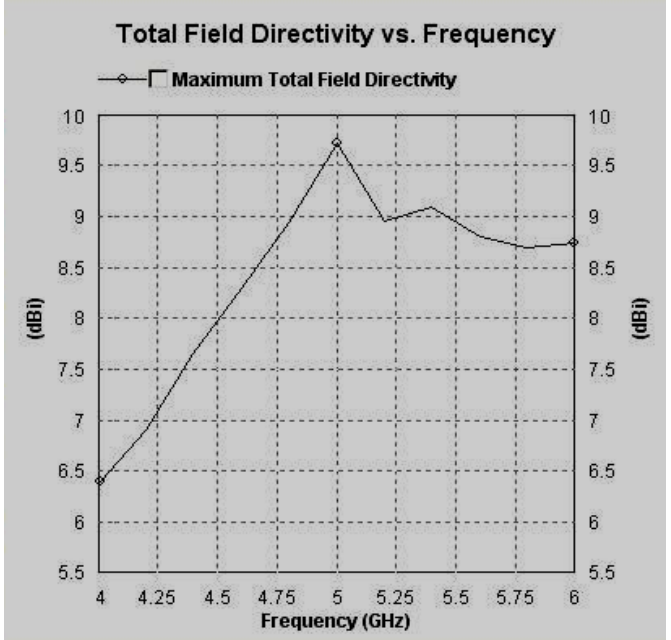

Fig.9: Field Directivity of DGS 1:2 Patch Antenna Array

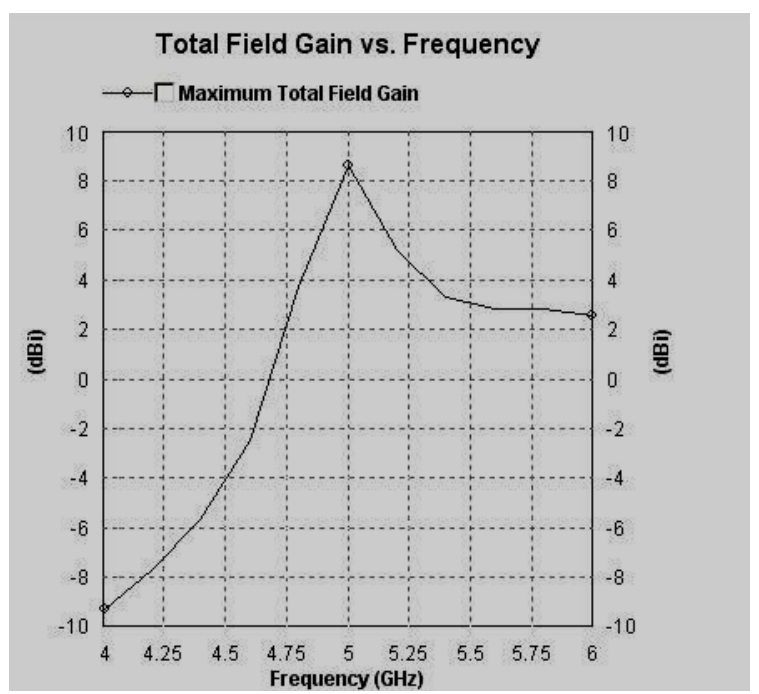

Fig.10: Gain of DGS 1:2 Patch Antenna Array

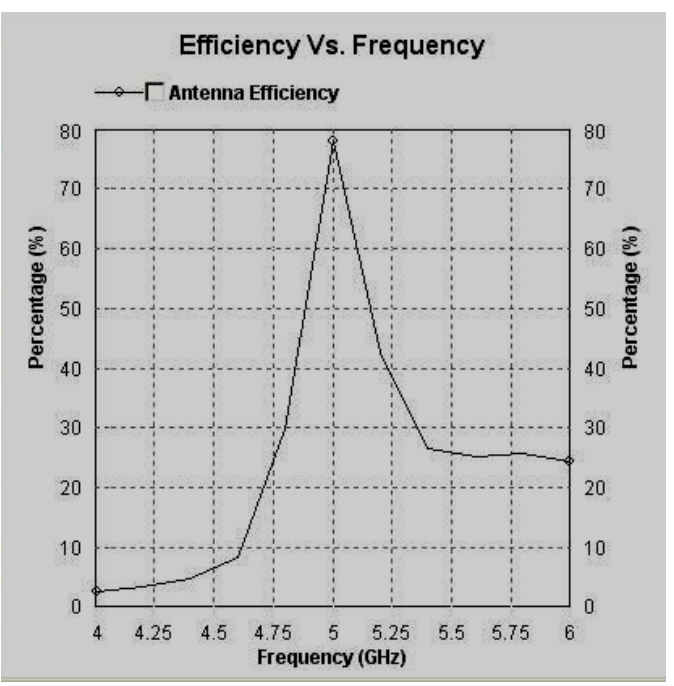

Fig.11: antenna efficiency of DGS 1:2 patch antenna array 


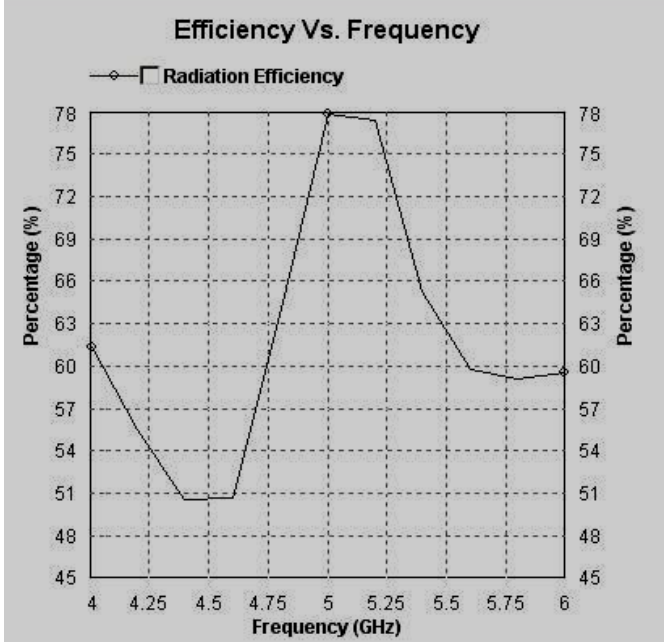

Fig.12: Radiation Efficiency of DGS 1:2 patch antenna array

\section{CONCLUSION}

In this paper Compact Patch Antenna Array using Defective Ground Structure on Feed Line Antenna is proposed, designed and analyzed through parametric studies using simulation software for C-band applications. Through the proposed design technique, the directivity of the antenna can be improved. Compared to many antennas proposed earlier, the proposed structure is a rather simple structure. The proposed antenna have achieved good stable radiation pattern and satisfied return loss. In addition, the proposed antenna has good radiation characteristics and gain, so it can emerge as an excellent candidate for wireless applications. As future scope on this design the bandwidth can be targeted to improve to make it more practical for the usages in wireless communication.

\section{REFERENCES}

[1] Hari Shankar Singh, Mayank Agarwal, Gaurav Kumar Pande, and Manoj Kumar Meshram, "A Quad Band Compact Diversity Antenna for GPSL1/WiFi/LTE2500 /WiMAX/HIPERLAN1 Applications," IEEE Antennas and Wireless Propagation Letters, Vol. 13, 2014.

[2] T. Huynh and K. F. Lee, "Single-Layer Single-Patch Wideband Microstrip Antenna, " Electronics Lett., vol. 31, no.16, pp. 1310-1312,August 1995.

[3] Deschamps, G., and Sichak, W. Microstrip Microwave Antennas. Proceedings of the Third Symposium on the USAF Antenna Research and Development Program, October 18-22, 1953.
[4] Robert, E. Conformal microstrip antennas and microstrip phased arrays. IEEE Transactions on AntennaPropagations, USA, 12, 1974.

[5] J. C. Liberti, T. S. Rappaport, "Smart Antennas for Wireless Communications: IS-95 and Third Generation CDMA Applications", Prentice Hall, New Jersey, 1999.

[6] H. F. AbuTarboush, H. S. Al-Raweshidy, "A Connected E Shape and U-Shape Dual-Band Patch Antenna for Different Wireless Applications", the Second International EURASIP Workshop on RFID Technology, July, 2008.

[7] F. Yang, X. Zhang, Y. Rahmat-Samii, "Wide-band Eshaped patch antennas for wireless communications," IEEE Trans. Antennas Propagation, vol. 49, 2001, pp. 1094-1100.

[8] AngYu, XuexiaZhang, "A Method to Enhance the Bandwidth of Microstrip Antennas Using a Modified E shaped patch," Radio and Wireless Conference, pp. 261 -264, August 2003.

[9] G .Kumar \& K .P .Ray,"Broadband microstrip antennas",Artech House,London, pp.11-14 2003,

[10] K. Wincza, S. Gruszczynski, 1. Borgosz, "Microstrip antenna array with series-fed 'through-element' coupled patches," Electronics Letters, vo1.43, no.9, pp.487-489, 26 April 2007.

[11] C. A. Balanis, Antenna Theory. PHI, 2002.

[12] M. S. Sharawi, A. B. Numan, M. U. Khan, and D. N Aloi (2012) "A Dual-Element Dual-Band MIMO Antenna System with Enhanced Isolation for Mobile Terminals, "IEEE Antennas Wireless Propag. Lett. vol. 11, pp.1006-1009.

[13] D.Guha, M.Biswas, and Y.M.M. Antar (2005) "Microstrip Patch Antenna with Defected Ground Structure for Cross Polarization Suppression", IEEE Antennas Wireless Propag. Lett. vol. 4, pp. 455-458

[14] K. H.Chiang and K. W. Tam (2008) "Microstrip Monopole Antenna With Enhanced Bandwidth Using Defected Ground Structure", IEEE Antennas Wireless Propag. Lett. vol. 7, pp. 532-535

[15] C. S. Kim, J. S. Park, D. Ahn, and J. B. Lim (2000) "A Novel 1-D Periodic Defected Ground Structure for Planar Circuits", IEEE Microwave Wireless Components Letters, vol. 10, no. 4, pp. 131-133 